MFN $=007133$

$01 \mathrm{SID} / \mathrm{SCD}$

025721

03 INPE-5721-PRE/1882

04 CEA

$05 \mathrm{~S}$

06 as

10 Clemesha, Barclay Robert

10 Simonich, Dale Martin

10 Batista, Paulo Prado

12 A long-term trend in the height of the atmospheric sodium layer: possible evidence for global change

$14 \quad 457-460$

30 Geophysical Research Letters

3119

325

40 En

41 En

$42<\mathrm{E}>$

58 DAE

$61<\mathrm{PI}>$

64 Mar. <1992>

68 PRE

76 AERONOMIA

83 An analysis of a long series of lidar measurements of the vertical distribution of atmospheric sodium shows the existence of a long-term trend in the centroid height of the layer. After making allowance for the sampling effects of the mean seasonal and diurnal variations in centroid height, it is found that the height of the layer fell by approximately 700 meters between 1972 and 1987. A regression analysis indicates a mean rate of fall of $49+-12 \mathrm{~m} \mathrm{yr}-1$, with a correlation coefficient of -0.33 , significant at the $99,99 \%$ level The observed change is consistent with long term trends in mesospheric temperatures detected by other

$90 \mathrm{~b}$ techniques.

91 FDB-19960313

92 FDB-MLR 


\title{
A LONG-TERM TREND IN THE HEIGHT OF THE ATMOSPHERIC SODIUM LAYER: POSSIBLE EVIDENCE FOR GLOBAL CHANGE
}

\author{
B.R. Clemesha, D.M. Simonich and P.P. Batista \\ Instituto Nacional de Pesquisas Espaciais - SCT São José dos Campos, São Paulo, Brasil
}

\begin{abstract}
An analysis of a long series of lidar measurements of the vertical distribution of atmospheric sodium shows the existence of a long-term trend in the centroid height of the layer. After making allowance for the sampling effects of the mean seasonal and diurnal variations in centroid height, it is found that the height of the layer fell by approximately 700 meters between 1972 and 1987 . A regression analysis indicates a mean rate of fall of 49 $\pm 12 \mathrm{~m} \mathrm{yr}^{-1}$, with a correlation coefficient of -0.33 , significant at the $99.99 \%$ level. The observed change is consistent with long term trends in mesospheric temperatures detected by other techniques.
\end{abstract}

\section{Introduction}

Regular measurements of the vertical distribution of atmospheric sodjum were rnade at Săo José dos Campos between 1972 and 1987. Various aspects of the results of these measurements have been presented in earlier papers (see, for example, Kirchhoff and Clemesha, 1973, Simonich et al., 1979, Clemesha et al., 1982, Batista et al., 1985, Batista et al, 1989). The purpose of the present note is to report the detection of a long-term trend in the centroid height of the layer.

The measurements

Although the determination of sodium density by lidar involves a difficult calibration problem, measurement of the centroid of the layer is independent of this calibration. Lidar measurements of the sodium layer use a photon counting receiver in which the numbers of detected photons are accumulated in range-gated bins. The timing of the bins is controlled by a crystal-controlled oscillator which, in our case, has a precision of a few parts in $10^{6}$, corresponding to less than a meter in height. The accuracy of the centroid height determined in any given measurement, however, is limited by the quantum noise in the photon counts rather than the precision of the timing. In our measurements this photon noise typically results in an error of less than $50 \mathrm{~m}$ in the nightly average. In this context it is important to note that the width of the height bins used to accumulate the signal photons has only a very small influence on the precision of the measurement. This parameter has a significant effect on the calculated centroid height only when the profile contains strong peaks which are narrower than the bin width. The analysis presented in this note is based on mean daily profiles, gen-

Copyright 1992 by the American Geophysical Union.

Paper number 92GL00123

$0094-8534 / 92 / 92 \mathrm{GL}-00123 \$ 03.00$ erated by averaging hourly means, typically representing at least 3 hours of measurements. Profiles averaged over more than a few hours almost never show height structures having dimensions less than a few $\mathrm{km}$. As a result of this, the fact that our measurements were made using a com" paratively wide height interval (a bin size of $2 \mathrm{~km}$ up to June, 1980 , and $1 \mathrm{~km}$ after that date) does not influence the precision of the centroid determination. In fact, the day-to-day fluctuations in the centroid height are many times greater than the error in the measurement, i.e. the geophysical noise is much more important than the measurement noise. Detajls of the INPE lidar and the data reduction technique used can be found in Kirchhoff and Clemesha [1973], Simonich et al. [1979] and Batista et al. [1985].

The daily mean centroid heights were used to determine monthly averages, giving equal weight to each daily mean value. A linear regression analysis of the monthly means results in a regression line corresponding to a decrease in the height of the sodium layer at a rate of 85 $\pm 15 \mathrm{~m} \mathrm{yr}^{-1}$, where the quoted error corresponds to the standard error of the estimate. The monthly means are plotted in Figure 1, along with the least mean squares tinear trend. Note that days on which sudden sodium layers were observed were not included in the analysis.

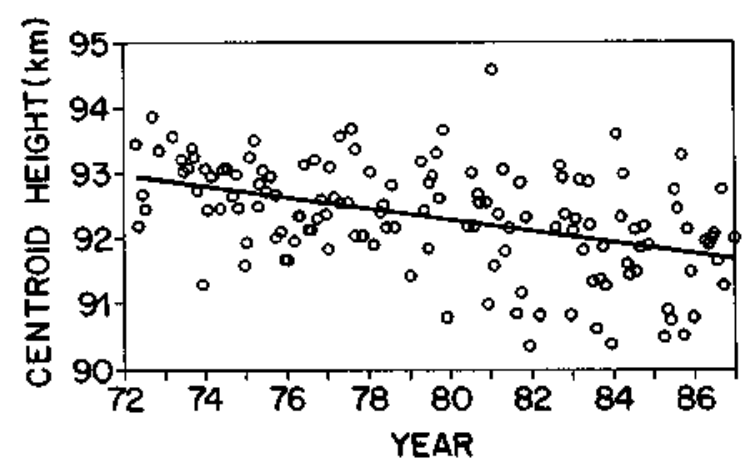

Fig. 1. Monthly means of the sodium layer centroid height.

The unexpected nature of the long term trend, detected in the analysis presented in Figure 1, leads to the suspicion that this trend might be an artifact of the data analysis. Care must be taken in using our observations to derive average trends in the sodium layer because the measurements were not made at regular intervals. In general, the data is biased towards winter nighttime conditions, with a maximum frequency for the early evening hours. The times of measurement, however, varied from day to day, month to month and year to year. The presence of diurnal and 
seasonal variations could thus lead to false trends in the averaged values. There is, in fact, a strong diumal variation in the centroid height of the sodium layer at our latitude [Clemesha et al., 1982, Batista et al., 1985] and a smaller, but significant, seasonal variation has also been detected [Clemesha et al., 1992]. Such effects are, indeed, likely to affect our analysis because, for example, our measurements were restricted to nighttime before 1980 , whereas some daytime measurements were made in later years.

There are two ways of dealing with the sampling problem: 1) use mean diurnal and seasonal trends to compensate the measurements for such variations; 2) analyze only data for a given time of day. To implement the first technique we adjusted our hourly average sodium profiles to the mean diurnal and seasonal trends shown in Figures 2 and 3 . The diurnal variation is based on a total of 59 days of 24-hour measurements made between the months of April and November. The use of a single average diurnal variation to adjust all data is justified by the fact that our 24-hr. measurements do not show a significant seasonal change in the diurnal variation of the centroid. The possibility that our diurnal variation may not be valid for the months of December through March is unimportant, because the measurements used in the analysis for this

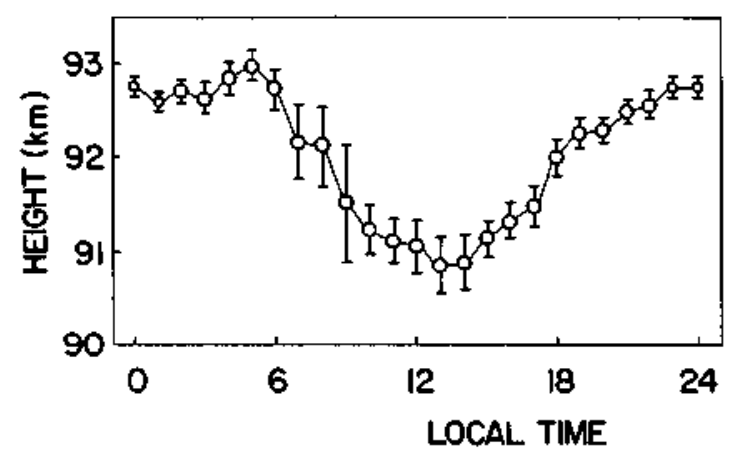

Fig. 2. Average 24-hour variation in the sodium layer centroid height.

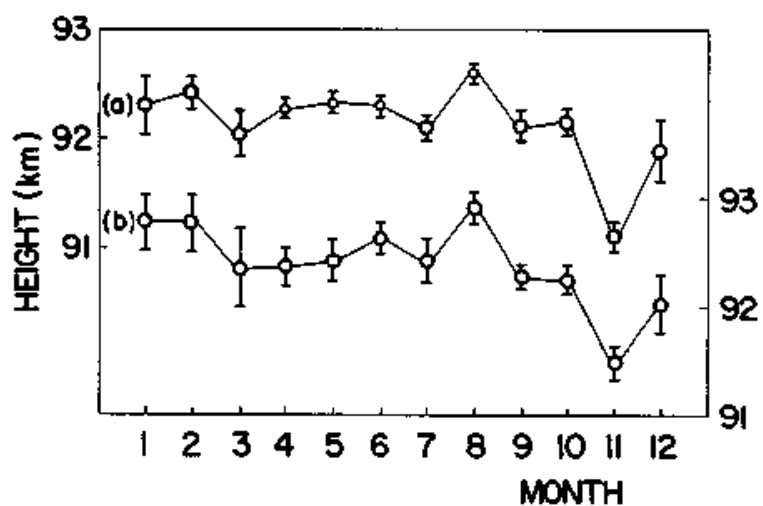

Fig. 3. Annual variation in the sodium layer centroid height based on: (a) diurnally adjusted data (left hand $y$-axis); (b) data for 1900-2200 hours only (right hand $y$ axis). part of the year were all made during the hours of darkness, when the centroid height shows only a small varjation. The adjustment involved a height displacement of each hourly profile by an amount equal to the difference in centroid height between the corresponding hourly average and the diurnal mean of the 24-hour measurements. After making this adjustment, daily mean centroid heights were calculated for the 710 days for which good quality data are available. These daily means were then used to determine the annual trend plotted in Figure 3 . The annual trend was subsequently used to remove the seasonal effect from the monthly mean centroid heights determined from the daily means. The results of this analysis are shown in Figure 4. As can be seen from this figure, removal of the diurnal and seasonal trends decreases the scatter in the monthly means. It also decreases, but by no means eliminates, the long term trend, which now becomes $49 \pm 12 \mathrm{~m} \mathrm{yr}^{-1}$.

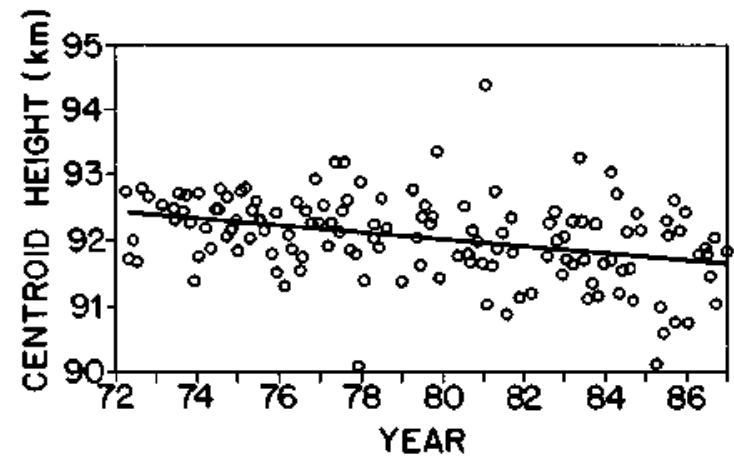

Fig. 4. Seasonal and diurnally adjusted monthly mean centroid heights.

We have also tried the second technique by analyzing only those profiles obtained between 1900 and 2200 hours. Restricting the data set in this way resulted in a number of months contajining data from one day only; such months were excluded from the analysis. The monthly mean centroid heights for 1900-2200, shown in Figure 5, indicate a linear trend of $55 \pm 13 \mathrm{~m} \mathrm{yr}^{-1}$. This value is in good agreement with that obtained from the seasonally and diumally

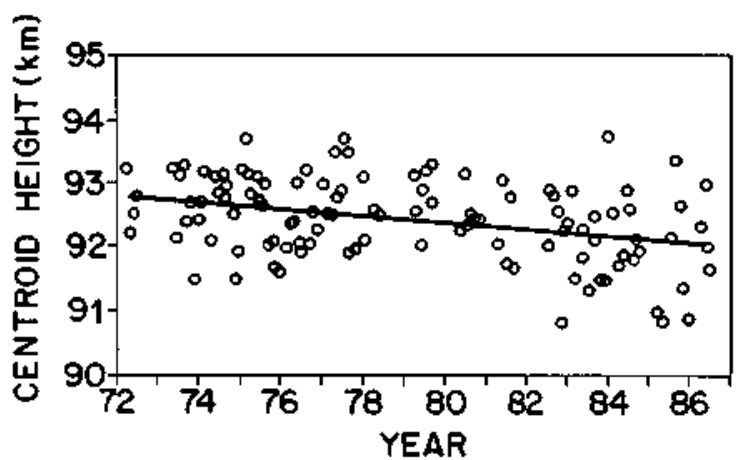

Fig. 5. Monthly mean centroid heights for $1900-2200$ hours. 
adjusted data. Note that the heights plotted in Figure 5 were not adjusted for the annual trend.

It might be thought that the a solar cycle effect could be responsible for part of the observed trend. To check this possibility we tried fitting an 11-year cycle to our adjusted monthly means. This analysis gave a value of $89 \pm 630 \mathrm{~m}$ for the amplitude of the 11-year cycle, so it is clear that a measurable solar cycle effect is not present in the centroid height of the sodium layer at our location.

\section{Discussion}

Our analysis of 15 years' of lidar measurements of atmospheric sodium shows that the centroid height of the sodium layer fell by approximately $700 \mathrm{~m}$. over the period of 15 years between 1972 and 1987 . The linear regression analysis of 138 adjusted monthly mean centroid heights results in a correlation coefficient of -.33 . This correlation is significant at the $99.99 \%$ level, making it extremely unlikely that the trend is not a real geophysical effect. A larger trend, obtained from the unadjusted data, is almost certainly the result of sampling effects together with the diurnal and seasonal variations.

The fact that our measurements span more than one solar cycle makes it unlikely that solar cycle effects are involved, and, in any case, an 11-year cycle fitted to our data has an amplitude of only $89 \mathrm{~m}$. The temptation to suggest that the observed trend is indicative of global change is obvious. Model calculations, such as those by Roble and Dickinson [1989], suggest that the mesopause region should be highly sensitive to changes in greenhouse gas concentrations, and that increases in such gases would lead to cooling of the mesosphere and thermosphere, with a consequent decrease in atmospheric density at all hejghts above about $50 \mathrm{~km}$. There is some experimental support for such cooling. According to Aikin et al. [1991] satellite measurements indicate a cooling of $3.5 \pm 0.5 \mathrm{~K}$ per decade at $50 \mathrm{~km}$, and Taubenheim et al. [1990] have reported a decrease of $10 \%$ in the reflection height of long radio waves between 1962 and 1987. Rayleigh lidar measurements, also reported by Aikin et al. [1991] apparently indicate a cooling of $2.5 \pm 1.0 \mathrm{~K}$ per decade at $50 \mathrm{~km}$, but there seems to be some inconsistency between this result and that presented by Hauchecorne et al. [1991], based on the same lidar data from Haute Provence. The latter work shows a cooling of $4 \mathrm{~K} /$ decade at $60-70 \mathrm{~km}$, but no trend at $50 \mathrm{~km}$. Since the source of the sodium layer is believed to be meteor ablation, a decrease in atmospheric density would presumably lead to a decrease in the height at which such ablation occurs. On the simplified assumption of a fixed temperature change at all heights above $50 \mathrm{~km}$, a decrease of $5 \mathrm{~K}$ would be necessary to produce a decrease of $700 \mathrm{~m}$ in the isobaric levels around $90 \mathrm{~km}$. This value is consistent with the $4 \mathrm{~K} /$ decade found by Hauchecorne et al. [1991]. A long-term increase in the frequency of occurrence of noctilucent clouds [Gadsden and Taylor, 1991] could also be the result of mesospheric cooling, although the same authors report the lack of any trend in the height of the clouds. Taubenheim et al. [1990] estimate that their results correspond to a temperature de- crease of $4 \mathrm{~K}$ over a period of 25 years. It is interesting to note that although Hauchecorne et al. [1991] state that the $4 \mathrm{~K} /$ decade change observed by Rayleigh lidar is only marginally significant at the $95 \%$ level, the data shown by Taubenheim et al. [1990] correspond to a correlation significant at a level of $99.99 \%$.

A problem with all the observations which suggest anthropogenic trends in the mesosphere and lower thermosphere, including the results presented here, is that they indicate trends which are considerably larger than those predicted by modelling studies. It is possible, of course, that changes in large scale meridional circulation, or in minor constituent concentrations could be responsible for the observed lowering of the sodium layer. With respect to the latter possibility, Roble and Dickinson [1989] predict large changes in some minor constituents, notably ozone, which might play an important role in sodium chemistry, but in view of our ignorance of the factors which control the vertical distribution of atmospheric sodium, there would appear to little point in further speculation in this direction.

Acknowledgements. This work was partially supported by the Fundo Nacional de Desenvolvimento Científico e Tecnológico (FNDCT) under contract FINEP-537/CT.

\section{References}

Aikin, A. C., M. L. Chanin, J. Nash and D. J. Kendig, Temperature trends in the lower mesosphere, Geophys. Res. Lett., 18, 416-419, 1991.

Batista, P. P., B. R. Clemesha, D. M. Simonich, and V. W. J. H. Kirchhoff, Tidal oscillations in the Atmospheric Sodium Layer., J. Geophys, Res., 90, 3881-3888, 1985.

Batista, P. P., B. R. Clemesha, I. S. Batista, and D. M. Simonjch, Characteristics of the sporadic sodium layers observed at, 23 degrees S, J. Geophys. Res., 94, 1534915358,1989

Clemesha, B. R., D. M. Simonich, P. P. Batista, and V. W. J. H. Kirchhoff, The Diurnal variation of atmospheric Sodium., J. Geophys. Res., 87, 181-186, 1982.

Clemesha, B.R., D.M. Simonich, H. Takahashi, P.P. Batista and Y. Sahai. The annual variation of the height of the atmospheric sodium layer at $23^{\circ} \mathrm{S}$ : Possible evidence for convective transport, $J$. Geophys. Res., accepted, 1992.

Gadsden, M. and M.J. Taylor, Anweisungen fur die photographischen Aufnahmen der leuchtenden Nachtwolken - 101 years on, paper presented at the meeting of the International Association for Meteorology and Atmospheric Physics, Vienna, $11-24$ August, 1991.

Hauchecorne, A. H., M. L. Chanin, and P. Keckhut, Climatology and trends of the middle atmospheric temperature $(33-87 \mathrm{~km})$ as seen by Rayleigh lidar over the South of France, J. Geophys. Res., 96, 15297-15309, 1991.

Kirchhoff, V. W. J. H., and B. R. Clemesha, Atmospheric Sodium Measurements at $23^{\circ} \mathrm{S}$, J. Atmos. Terr. Phys., 35, 1493-1495, 1973.

Roble, R. G., and R. E. Dickinson, How will changes in 
carbon dioxide and methane modify the mean structure of the mesosphere and thermosphere?, Geophys. Res. Lett., 16, 1441-1444, 1989

Simonich, D. M., B. R. Clemesha, and V. W. J. H. Kirchhoff, The Mesospheric Sodium Layer at $23^{\circ} \mathrm{S}$ : Nocturnal and Seasonal variations, J. Geophys. Res., 84, 1543$1550,1979$.

Taubenheim, J., G. von Kossart and G. Entzian, Evidence of $\mathrm{CO}_{2}$-induced progressive cooling of the middle at- mosphere derived from radio observations, $A d v$. Space Res., 10(10), 171-174, 1990.

B.R. Clemesha, P.P. Batista and D.M. Simonich, Instituto Nacional de Pesquisas Espaciais, C.P. 515, 12201, São José dos Campos, São Paulo, Brazil.

Received: December 30, 1991

Accepted: January 10, 1992 